\title{
SOME PERFORMANCE MEASURES FOR VACATION MODELS WITH A BATCH MARKOVIAN ARRIVAL PROCESS
}

\author{
Submitted to Journal of Applied Mathematics and Stochastic Analysis \\ SADRAC K. MATENDO \\ Universiti de Mons-Hainaut \\ Place Warocqui, 17, B-7000 MONS (Belgium) \\ e-mail:ematendo@vml.umh.ac.be
}

We consider a single-server infinite capacity queueing system with a batch Markovian arrival process (BMAP).In particular, BMAP's are the batch Poisson arrival process, Markovian arrival process (MAP's), many batch arrival processes with correlated inter-arrival times and batch sizes, and superpositions of these processes. We note that the MAP includes phase-type $(\mathrm{PH})$ renewal processes and non-renewal processes such as the Markov modulated Poisson process (MMPP).

The server applies Kella's vacation scheme, i.e., a vacation policy where the decision of whether to take a new vacation or not, when the system is empty, depends on the number of vacation already taken in the current inactive phase. This exhaustive service discipline includes the single vacation T-policy, T(SV), and the multiple vacation T-policy, $\mathrm{T}(\mathrm{M})$. The service times are i.i.d. random variables, independent of the inter-arrival times and the vacation durations. Some important performance measures such as the distribution functions and means of the virtual and the actual waiting time processes are given. Finally, a numerical example is presented. 


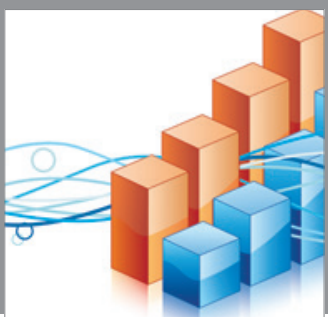

Advances in

Operations Research

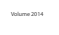

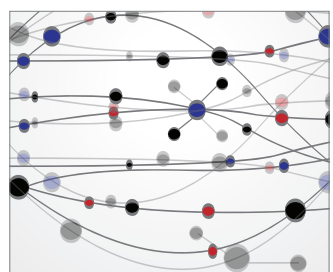

\section{The Scientific} World Journal
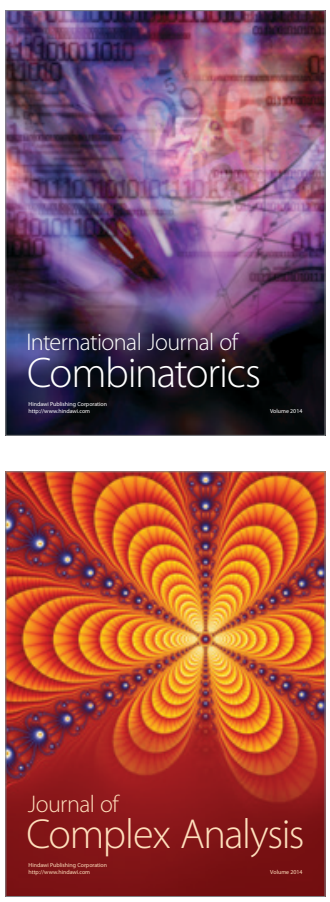

International Journal of

Mathematics and

Mathematical

Sciences
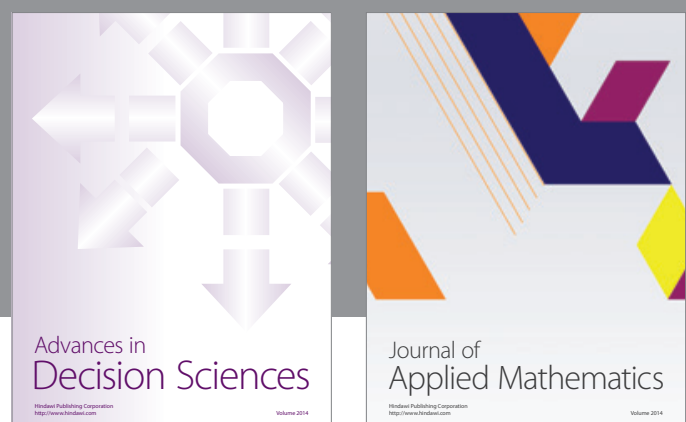

Journal of

Applied Mathematics
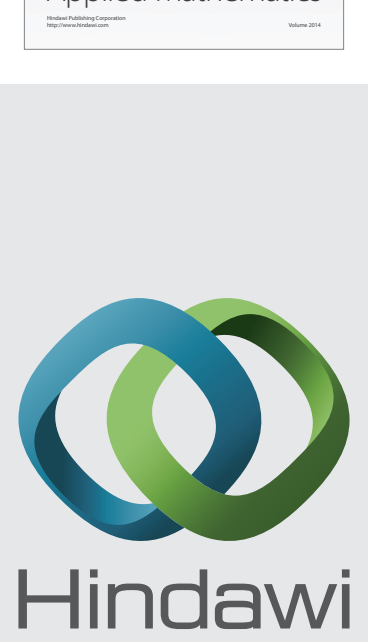

Submit your manuscripts at http://www.hindawi.com
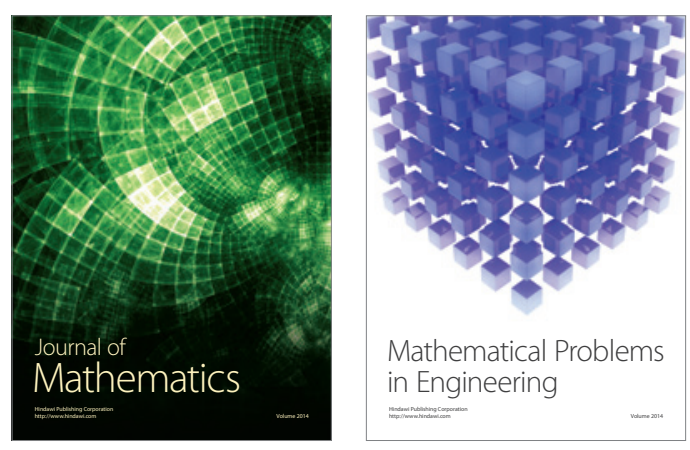

Mathematical Problems in Engineering
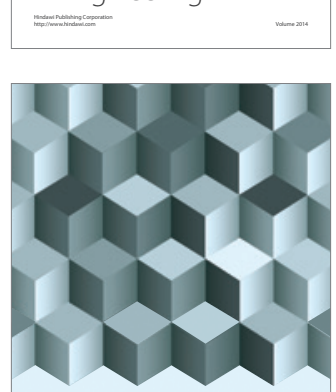

Journal of

Function Spaces
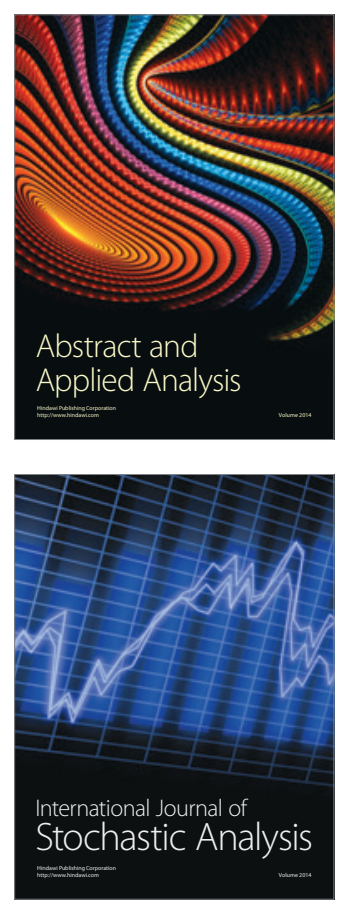

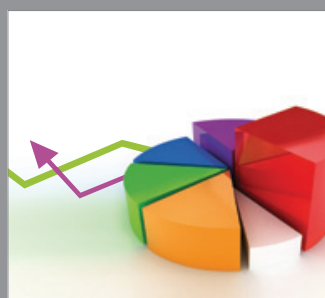

ournal of

Probability and Statistics

Promensencen
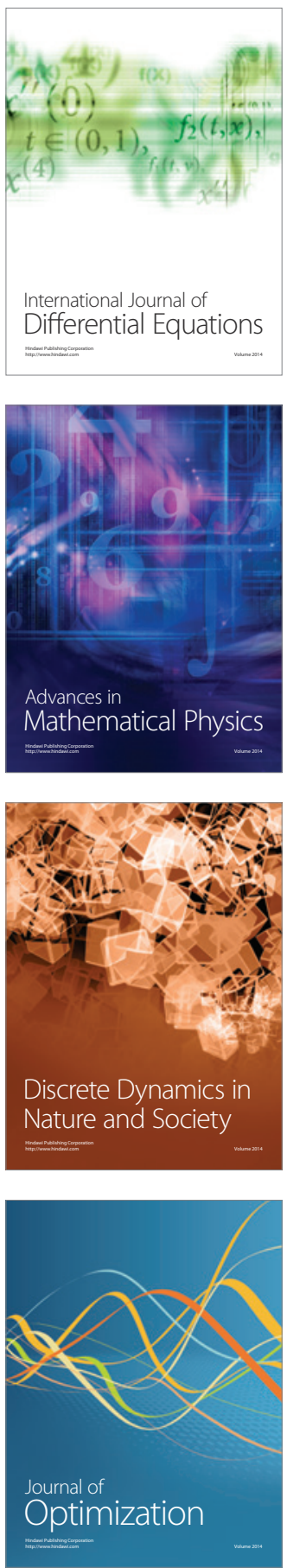